Journal of Astronomical Instrumentation, Vol. 6, No. 2 (2017) 1740001 (7 pages)

(C) The Author(s)

DOI: $10.1142 / \mathrm{S} 2251171717400013$

\title{
Recent Highlights of Scientific Ballooning in Japan
}

\author{
H. Fuke* \\ Institute of Space and Astronautical Science \\ Japan Aerospace Exploration Agency (JAXA/ISAS) \\ Sagamihara, Kanagawa 252-5210, Japan \\ fuke.hideyuki@jaxa.jp \\ Received 2016 November 22; Accepted 2017 February 21; Published 2017 March 31
}

\begin{abstract}
Since 2008, the Japan Aerospace Exploration Agency (JAXA) has carried out annual domestic balloon campaigns from Taiki Aerospace Research Field (TARF). Productive results have been obtained by many projects in academic fields such as atmospheric science, space engineering, cosmic-ray physics, and astronomy. In 2013, an 80,000- $\mathrm{m}^{3}$ balloon made from a 2.8- $\mu \mathrm{m}$ ultra-thin polyethylene film reached an altitude of $53.7 \mathrm{~km}$, equaling the world record for the altitude of an unmanned balloon. In 2015, JAXA carried out a balloon campaign from Alice Springs in Australia as a precursor of future sustainable overseas activities to compliment the domestic ones at TARF. In this paper, we discuss recent highlights of and future prospects for Japanese scientific ballooning.
\end{abstract}

Keyword: Balloons.

\section{Introduction}

The Japan Aerospace Exploration Agency (JAXA) has been conducting scientific ballooning in Japan for the past 50 years. The enterprise began in 1966, and from 1971 to 2007, around 400 scientific balloons were launched from the former Sanriku Base (Yoshida et al., 2008). Since 2008, annual domestic balloon campaigns have been conducted from Taiki Aerospace Research Field (TARF) in Hokkaido (Fuke et al., 2010a,b).

TARF is located in an ample plain on the seafront of the Pacific Ocean. Here, a semi-dynamic launching method has been developed using a dedicated "sliding launcher" and a huge hangar (Fuke et al., 2009). For safety, balloons are inflated inside the hangar to minimize the risk of being damaged by wind gusts. Once launch has been approved, the sliding launcher moves the balloon out of the hanger and launches it.
In order to prolong the flight while ensuring safe recovery within the limited national territory of Japan (particularly given its relatively high population density), operations are conducted using the so-called "boomerang" flight mode (Nishimura \& Hirosawa, 1981). As shown in Fig. 1, the balloon's ascent is halted firstly after launch by removing the free lift, whereupon the balloon is carried eastward over the sea by the strong tropopause jet stream. The balloon's ascent is then resumed by dropping the ballast, whereupon the balloon is carried back westward at the float altitude. The flight is terminated near the coast, and both the separated balloon and its payload are recovered at sea by boats or ships. The flight windows at TARF are MayJune and August-September, when there is usually both a strong westerly jet stream and a moderate easterly wind in the upper stratosphere to facilitate a boomerang flight.

* On behalf of the Scientific Ballooning Research and Operation Group.

This is an Open Access article published by World Scientific Publishing Company. It is distributed under the terms of the Creative Commons Attribution 4.0 (CC-BY) License. Further distribution of this work is permitted, provided the original work is properly cited. 


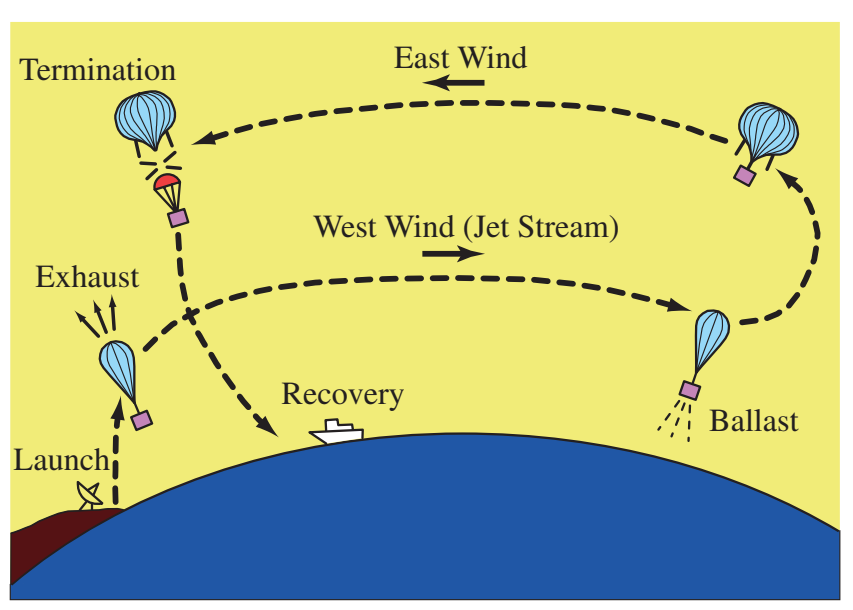

Fig. 1. Schematic of a boomerang flight operation.

Using this boomerang-flight operation from TARF, productive results have been achieved by many projects from various academic fields. For example, in atmospheric science, a series of cryogenic samplings of the stratospheric atmosphere have been carried out (Aoki et al., 2003). Combined with the data obtained from flights from the former Sanriku base, the absolute concentrations of various gaseous components (e.g. greenhouse gases and isotopes) have been measured for more than 30 years, and the accumulated data have been used to elucidate the transport and chemical processes in the stratosphere. Additionally, a gravitational separation of atmospheric components in the stratosphere was discovered (Ishidoya et al., 2013). The whole-air sampling method allows high-resolution, high-precision measurements of local absolute concentrations, and is complementary to other methods such as remote sensing and in situ real-time measurements.

Furthermore, balloon flights can be used to verify next-generation space technologies. As an example, the deployment of a prototype solar sail was demonstrated from a balloon floating in free space, where there is less air resistance (Shirasawa et al., 2009). These tests contributed to the success of Ikaros, the first solar-sail spacecraft mission (Mori et al., 2014).

Research has also been pursued on space environment utilization. Dropping a rocket-shaped drag-free capsule from a balloon float altitude gives around $30 \mathrm{~s}$ of free-fall during which a micro-gravity environment can be sustained. By using a doubleshell structure, the inner floating shell experiences a high-quality micro-gravity of the order of $10^{-3}-10^{-4} \mathrm{~g}$, which is comparable to that in the
International Space Station (ISS) (Ishikawa et al., 2009, 2013). This balloon-borne micro-gravity platform, with its half-a-minute of good microgravity, is complementary to other methods such as drop towers, parabolic aircraft flights, and the Japanese Experiment ("Kibo") Module of the ISS.

Of the research fields that use Japanese scientific ballooning, astronomy and astrophysics are the most traditional. Generally, experiments in these fields require flights of longer duration than those in other fields in order to obtain sufficient amounts of data. However, for reasons discussed below, the flight duration available at TARF is becoming limited. Hence, astronomical and astrophysical balloon flights from TARF are being used less for observations and more for engineering demonstrations and technical validations. For example, an engineering balloon flight of the CALorimetric Electron Telescope (CALET) was carried out prior to its delivery to the ISS (Niita et al., 2015). A similar flight of the General Anti-Particle Spectrometer (GAPS) represented the first fully fledged international collaborative experiment at TARF (Fuke et al., 2014a).

\section{Australian Balloon Campaign}

Recently, probably because of abnormal global weather patterns, fluctuations in the jet stream over Japan have increased. Boomerang flights require stable and opposing wind directions of both the jet stream and the stratospheric wind; the more these fluctuate, the fewer the flight opportunities, especially for longer flights. In addition to unhelpful weather conditions, tighter safety regulations and a lack of resources have also limited the domestic ballooning activities at TARF. Given these constraints, it is now particularly difficult to increase balloon size, payload weight and flight duration.

Therefore, in 2015, JAXA carried out a balloon campaign from Alice Springs in Australia as a precursor of future sustainable overseas activities. Alice Springs is located in the middle of Australia in vast and relatively unpopulated territory. Alice Springs Airport has half a century of history as a balloon launch site, and thus has the necessary facilities for balloon operations. By utilizing these existing facilities and previous local know-how, we expect that a balloon campaign from Alice Springs would compliment the domestic campaigns from TARF. It would be particularly advantageous in relation to 

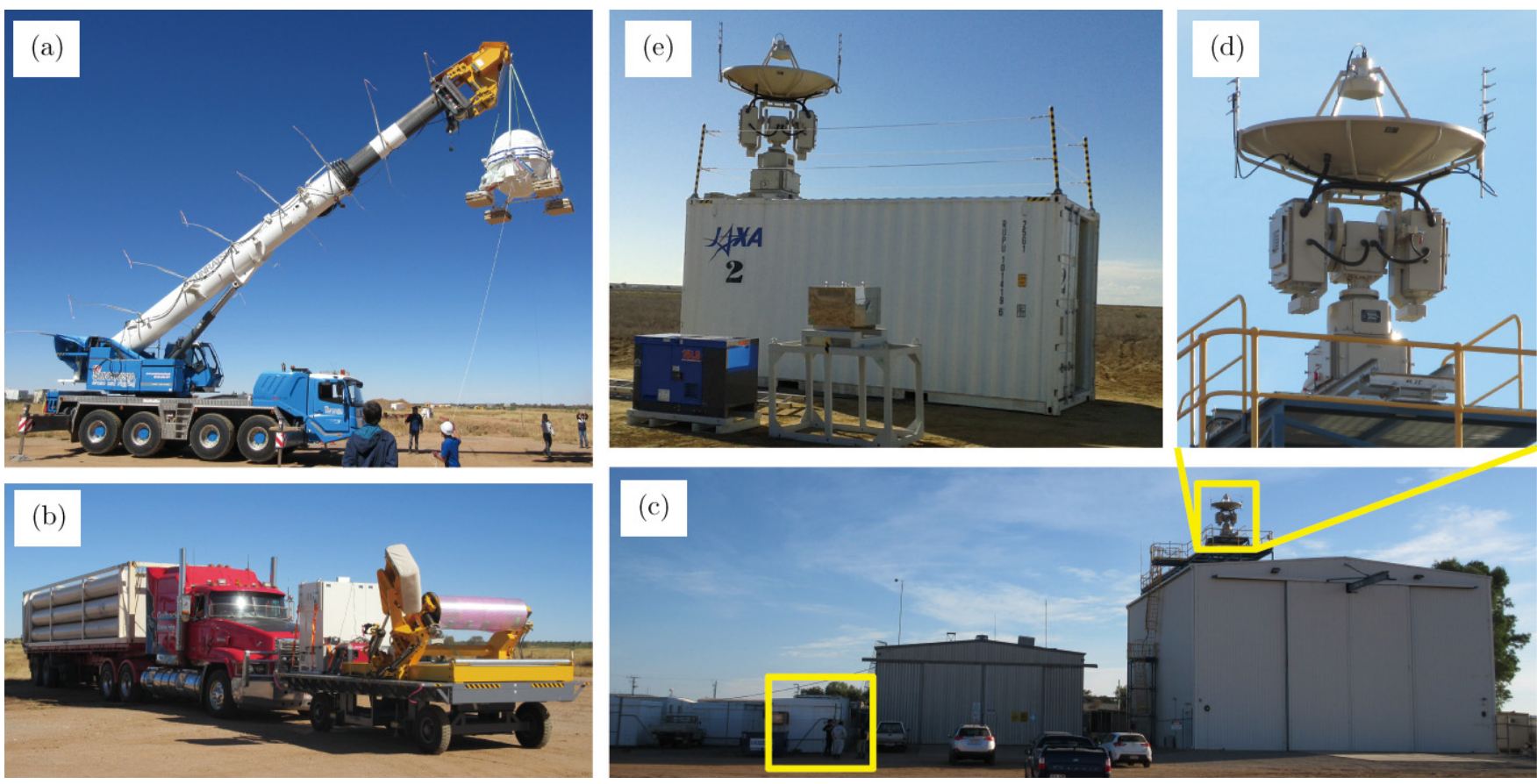

Fig. 2. (Color online) (a) Launch head (yellow part) connected to the boom top of a crane vehicle. The GRAINE payload is hanging from the release mechanism of the launch head. (b) Dolly with a launch spool and a gas controller, coupled to the front pin of a helium-gas-cylinder trailer. (c), (d) Antenna set on the rooftop of a hangar, connected to a mobile station on the ground at Alice Springs. (e) Stand-alone downrange station at Longreach.

longer flight durations, recovery over land and observations in the Southern Hemisphere.

In order to carry out a balloon campaign, we transported various dedicated equipment to Australia. Figure 2(a) shows a launch head connected to the boom top of a crane vehicle. This launch head was developed specifically for the Australian campaign on the basis of an electric release mechanism that had been well proven in Japan. Figure 2(b) shows a dolly with an on-board spool and gas controller, both of which were also developed specifically and are similar to devices proven in Japan. The dolly is coupled with the prime mover of a helium-gas-cylinder trailer. Mobile stations for telemetry, tracking and command systems were also brought to Australia. At Alice Springs, an antenna set was mounted on a hangar built by NASA (Fig. 2(d)) and was connected to a mobile station on the ground (left side in Fig. 2(c)). In addition, we set up a downrange site at Longreach, $1000 \mathrm{~km}$ east of Alice Springs; Fig. 2(e) shows a mobile station there. At Alice Springs, we established a meteorological system that includes an all-in-one weather sensor and a Doppler-sodar wind profiler. The measured weather data is monitored continuously back in Japan via the Internet to accumulate the year-round local weather data.
In the 2015 Australian campaign, a prototype payload was launched for the Gamma-Ray AstroImager with Nuclear Emulsion (GRAINE) project (Takahashi et al., 2016). This project aims to observe astrophysical gamma rays with a high angular resolution using an emulsion-film telescope. The science payload weighed around $500 \mathrm{~kg}$ and was modestly sized $(2.4 \mathrm{~m}(\mathrm{~L}) \times 2.4 \mathrm{~m}(\mathrm{~W}) \times 3.0 \mathrm{~m}(\mathrm{H}))$. The balloon was launched on the morning of 2015 May 12 (Fig. 3(a)). After a 14-h flight at a float altitude of around $37 \mathrm{~km}$, the GRAINE payload landed near Longreach and was recovered safely and quickly, making for a very successful flight (Fig. 3(b)).

Based on the success of this precursor campaign, we plan to conduct a multiple-flight Australian campaign every few years. We intend to extend the maximum payload weight and flight duration to around two tons and a few days, respectively.

\section{Ultra-thin-film Balloons}

In parallel with the approach to massive balloon experiments described in Sec. 2, we have addressed the challenge of reaching higher altitudes. In order to explore the mesosphere more easily with light payloads, since 1991 we have been incrementally 


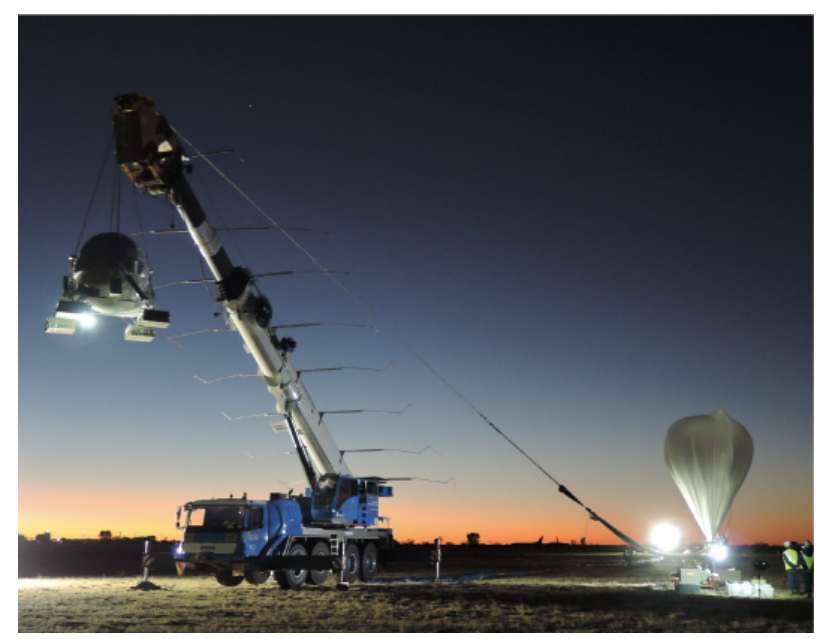

(a)

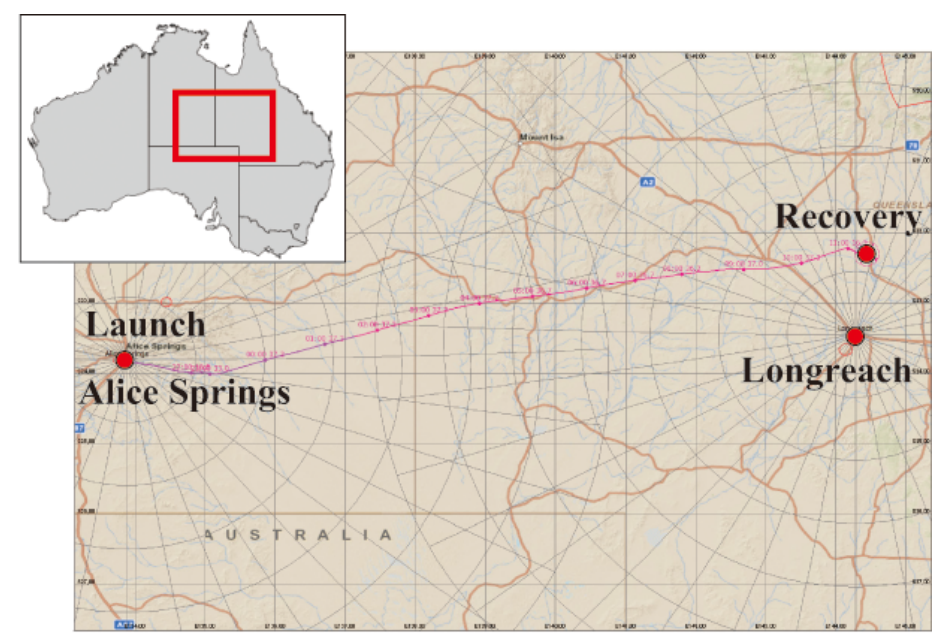

(b)

Fig. 3. (a) The GRAINE payload attached to a balloon just before launch. (b) Trajectory of the GRAINE flight.

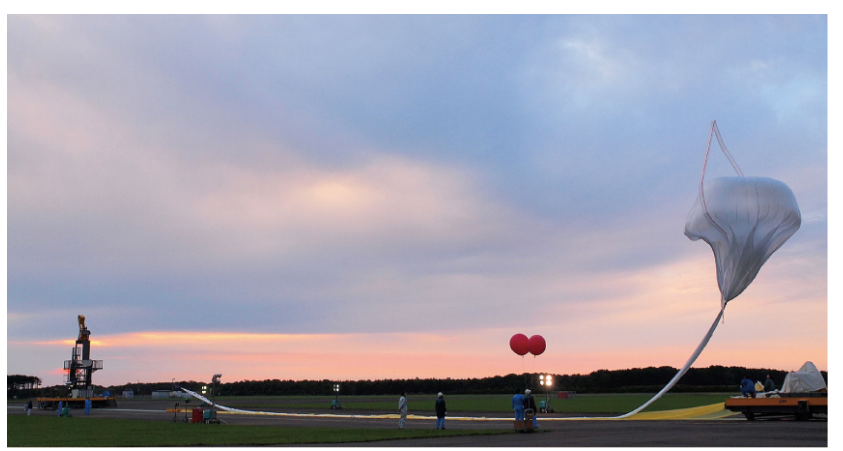

(a)

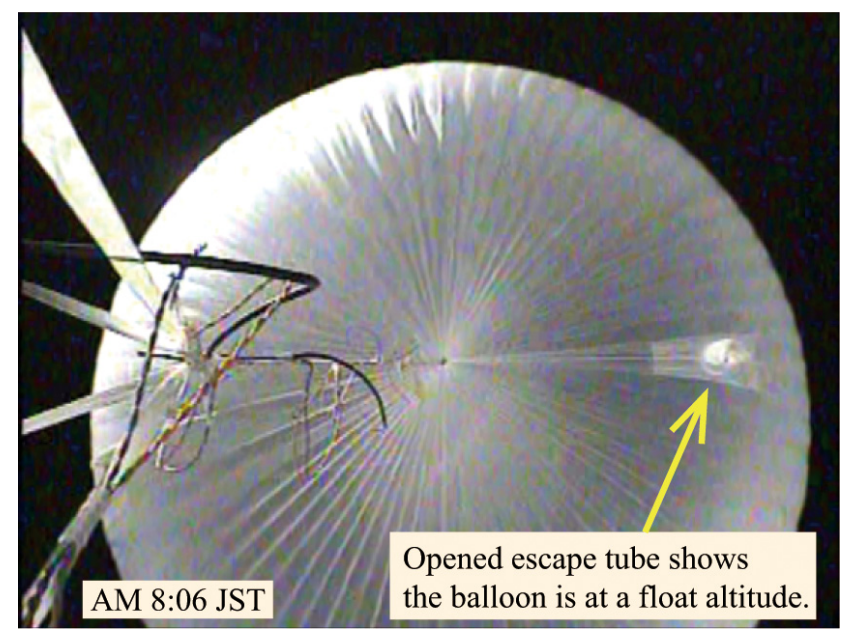

(c)

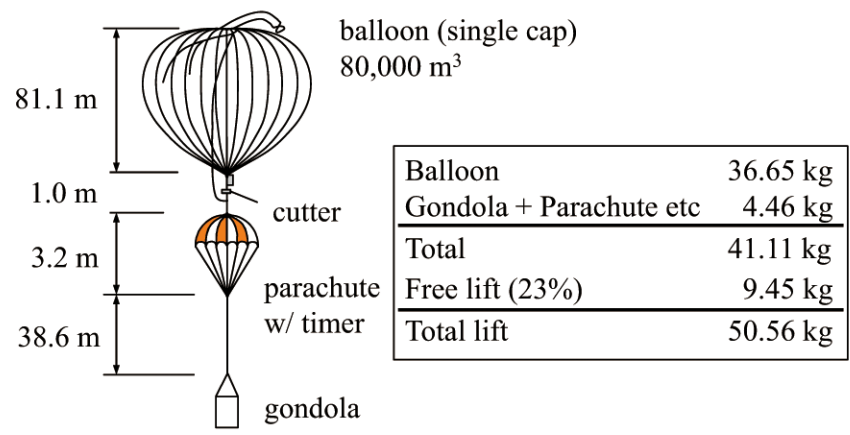

(b)

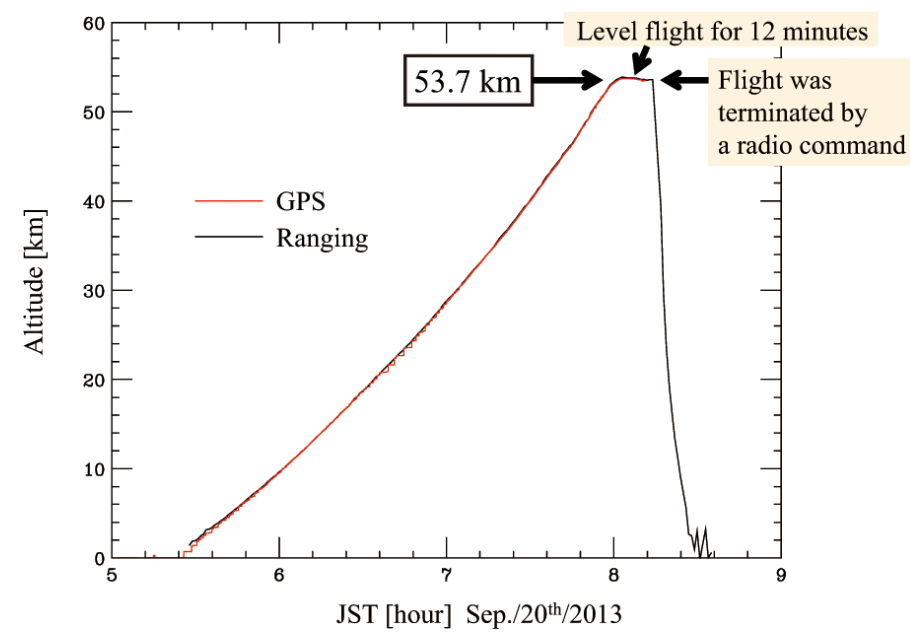

(d)

Fig. 4. A balloon launched from TARF on the morning of 2013 September 20, which equaled the world record altitude of $53.7 \mathrm{~km}$ : (a) launch, (b) breakdown lists of weight and length of flight train, (c) a picture captured from video taken by a camera on the payload, showing the balloon escape tube fully open and (d) altitude profile of the flight (GPS and ranging data agreed and indicate that the balloon floated at $53.7 \mathrm{~km})$. 
developing lightweight balloons made from very thin polyethylene films. In 1997, a balloon with a volume of $120,000 \mathrm{~m}^{3}$ made from a $5.8-\mu \mathrm{m}$-thick film lifted an 11.8-kg payload to an altitude of $50.2 \mathrm{~km}$, which at the time was the record balloon altitude in Japan (Yamagami et al., 1998; Matsuzaka et al., 2000). Next, we developed a thinner polyethylene film with a thickness of $3.4 \mu \mathrm{m}$ using metallocene as a catalyst (Saito et al., 2002). In 2002, a balloon with a volume of $60,000 \mathrm{~m}^{3}$ made from this $3.4-\mu \mathrm{m}$ thick film lifted a $4.6-\mathrm{kg}$ payload to an altitude of $53.0 \mathrm{~km}$, which equaled the world record altitude at the time for an unmanned balloon (Yamagami et al., 2004). We then developed an even thinner film with a thickness of $2.8 \mu \mathrm{m}$ (Saito et al., 2006); however, we encountered difficulties when trying to launch balloons made from this ultra-thin film. Based on the lessons learned from three successive failures to float a $60,000-\mathrm{m}^{3} 2.8-\mu \mathrm{m}$-thick balloon, we reassessed all the key issues involved in launching an ultra-thin-film balloon. For example, the balloon design, the balloon manufacturing procedure, the launch spool, the collar, the release mechanism and the launch method were all modified to safeguard both the balloon itself and its treatment (Saito et al., 2012). Unfortunately, in 2011, we failed in an attempt to float a modified 2.8$\mu \mathrm{m}$-thick film balloon with a volume of $80,000 \mathrm{~m}^{3}$ on which a single cap was put. Because this failure was caused by a malfunction of an onboard flight-termination device, the onboard devices were upgraded to improve their reliability. To secure the flight termination, we also modified the design of the balloon rip panels from an "I" shape to the inverted "V" shape used for regular balloons.

Finally, on 2013 September 20, we succeeded in launching a balloon with a volume of $80,000 \mathrm{~m}^{3}$ made from a $2.8 \mu$ m-thick film (Fig. 4(a)). Hanging a $3.2-\mathrm{kg}$ payload, this balloon reached an altitude of $53.7 \mathrm{~km}$, again equaling the world record for the highest unmanned balloon. The balloon altitudes as measured by both a global positioning system (GPS) and ranging (Nishimura, 1993) were consistent (Figs. 4(b) and 4(d)). From the upward video taken by an onboard camera, we confirmed that the escape tube (horse-tail type) of the balloon opened fully at float, thus showing that the balloon had fully deployed (Fig. 4(c)). After floating for $12 \mathrm{~min}$, the flight was terminated by radio command because the balloon was approaching the boundary of the notified splashdown area.
Some of the types of ultra-thin-film balloon that we developed are now being used for high-altitude scientific flights, especially for atmospheric observations between the upper stratosphere and the lower mesosphere. In order to enhance this capacity to contribute to science, we plan to develop a reinforced ultra-thin-film balloon. The immediate goal is to lift an $18-\mathrm{kg}$ payload (10 $\mathrm{kg}$ of which would be for scientific purposes) to a minimum altitude of $50 \mathrm{~km}$. To demonstrate this ability, we plan to float a reinforced capped balloon with a volume of $80,000 \mathrm{~m}^{3}$ made from a $3.4-\mu \mathrm{m}$-thick film at an altitude of $50.0 \mathrm{~km}$ while hanging a $18-\mathrm{kg}$ payload. We are developing a new type of lightweight load tape that will save on balloon weight. Each piece of bus equipment (e.g. telecommunication modules and security devices) will be made lighter too.

\section{Super-pressure Balloons}

We have also developed technology for super-pressure balloons, which have a closed (or pressurized) envelope and are expected to drastically elongate balloon flight durations. We proposed the so-called "Tawara" type balloon design (Izutsu et al., 2010), which has been described as "a lobed pumpkin divided along the equator" plus "a lobed cylinder with the same cross-section inserted into the equator gap". Tawara has much better deployment stabilities than those of the normal design of pumpkinshaped lobed super-pressure balloons, a fact that was confirmed by both ground testing (Fuke et al., 2011) and numerical calculations (Nakashino, 2012).

Since then, however, the Tawara development has been forced to slow down. The main reason for this has been an additional requirement from the Japan Coast Guard to eliminate the possibility of balloons sinking at sea in order to minimize the risk of marine pollution. In contrast to normal zeropressure balloons, the original Tawara model was made from a film and a load rope that were denser than water. Therefore, we modified Tawara by using lighter materials. The envelope film was changed from multi-layer "BH25" film (specific gravity $\rho=1.06)$ to a $30-\mu$ m-thick polyethylene film $(\rho=0.90)$. The original para-aramid (Kevlar) load rope $(\rho=1.44)$ was replaced by one made from ultra-high-molecular-weight polyethylene (UHMWP) $(\rho=0.97)$. In addition, the rip panel design was improved by applying a design similar to the one used for regular zero-pressure balloons. 


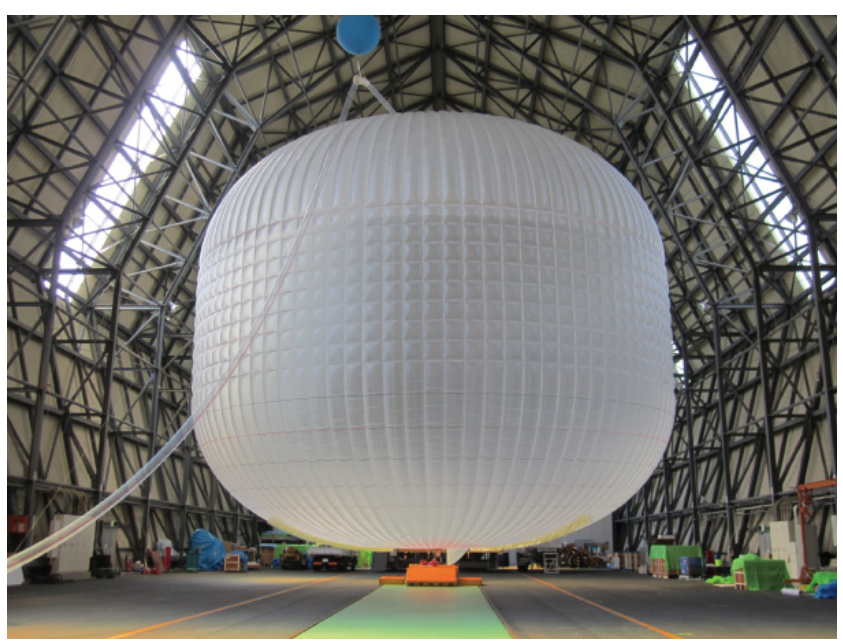

Fig. 5. A 5000- $\mathrm{m}^{3}$ Tawara-type super-pressure balloon made from lightweight materials being fully deployed in a hangar to test its deployment stability and pressure resistance.

In 2013, by means of indoor ground testing using a scaled model of a Tawara balloon, we confirmed that the deployment stability of Tawara would not be degraded by using these lighter materials; a sufficient inner-pressure resistance could still be maintained (Fig. 5). The next step is to perform a short-duration flight of a small Tawaratype super-pressure balloon to demonstrate the usefulness of the Tawara concept. However, in order to fly super-pressure balloons globally for actual flight operations, it will be necessary to secure international cooperation.

\section{Adaptation to Greater Sophistication and Diversity}

As we discussed, JAXA's balloon activities have contributed to various fields of science and technology. In Japan, however, resources such as man-power, budgets, and flight opportunities are becoming insufficient to keep up with the demands from balloon users for ever greater sophistication and diversity. Therefore, in addition to the balloon flights provided by JAXA, Japanese space scientists are turning to the valuable flight opportunities offered by foreign space agencies in order to carry out their cutting-edge research. In fact, diverse experiments are already being either carried out or planned in international collaborations to utilize the balloon flight opportunities offered by agencies such as NASA, CNES and SSC.

Another option is for the users themselves to conduct balloon campaigns. As an example of this approach, the team mentioned in Sec. 1 that is engaged in cryogenic sampling of the stratospheric atmosphere conducts its own balloon campaigns at various sites in addition to the full-scale experiments at TARF. The team has developed a compact version of a cryogenic sampler that can be launched by a small balloon (Morimoto et al., 2009). Several scientific members of the team have been trained to launch small plastic balloons. Because it is essential to sample the atmosphere at various latitudes in order to be able to consider the global atmospheric circulation, the team has conducted balloon campaigns around the world: between 2007 and 2013 at Syowa station, Antarctica (e.g. Morimoto et al., 2009), in 2012 from a ship in the eastern Pacific Ocean near the equator (Fuke et al., 2014b), and in 2015 at Biak, Indonesia.

\section{Summary}

JAXA operates domestic balloon campaigns from TARF that contribute to diverse scientific and technological endeavors. Facing increasingly limited flight opportunities caused by climate change and other external factors, we plan to conduct a balloon campaign in Australia every few years to complement our domestic campaigns. A precursor Australian campaign was successfully staged in 2015. As a development of next-generation balloon technologies, a number of balloons made from ultra-thin films were launched and demonstrated. In 2013, a balloon made from a 2.8- $\mu$ m-thick film set a new record altitude of $53.7 \mathrm{~km}$ for an unmanned balloon. We intend to expand the weight capacity of these ultra-thin-film balloons to explore the science of the mesosphere. In addition to these various activities, we intend to strengthen international cooperation to increase the diversity of flight opportunities available to the scientific community.

\section{Acknowledgments}

We thank DAIKO Co., Ltd. and Fujikura Parachute Co., Ltd. for their continuous support in developing launch equipment and plastic balloons, respectively. We give heartfelt thanks to the local government, residents, and all relevant parties at Taiki for their support in carrying out balloon operations at TARF. We express our sincere thanks to R. Sood, D. Sullivan, the University of New 
South Wales (UNSW) and the Commonwealth Scientific and Industrial Research Organisation (CSIRO) for their professional support in implementing the Australian balloon campaign in 2015. We would also like to express our deepest gratitude to H. Endo, Y. Kato, A. Kukita, S. Tsukui and K. Yamada for their skillful work in executing the Australian campaign.

\section{References}

Aoki, S., Nakazawa, T., Machida, T. et al. [2003] Tellus 55B, 178.

Fuke, H., Akita, D., Iijima, I. et al. [2009] Trans. Jpn. Soc. Aeronaut. Space Sci., Space Technol. Jpn. 7, Tm7.

Fuke, H., Akita, D., Iijima, I. et al. [2010a] Adv. Space Res. 45, 490.

Fuke, H., Akita, D., Iijima, I. et al. [2010b] Trans. Jpn. Soc. Aeronaut. Space Sci., Space Technol. Jpn. 8, Tm25.

Fuke, H., Izutsu, N., Akita, D. et al. [2011] Adv. Space Res. 48, 1136.

Fuke, H., Ong, R. A., Aramaki, T. et al. [2014a] Adv. Space Res. 53, 1432 .

Fuke, H., Iijima, I., Izutsu, N. et al. [2014b] J. Atmos. Ocean. Technol. 31(7), 1540

Ishidoya, S., Sugawara, S., Morimoto, S. et al. [2013] Atmos. Chem. Phys. 13, 8787.

Ishikawa, T., Hashimoto, T., Sawai, S. et al. [2009] Trans. Jpn. Soc. Aeronaut. Space Sci., Space Technol. Jpn. 7, Ph29.

Ishikawa, T., Maru, Y., Sawai, S. et al. [2013] New microgravity experiment system using free-fall capsule from a high altitude balloon, in Proc. 29th Int. Symp. Space Technology and Science, June 2-9, 2013, Nagoya-Aichi, Japan, 2013-m-01.
Izutsu, N., Akita, D., Fuke, H. et al. [2010] Trans. Jpn. Soc. Aeronaut. Space Sci., Aerosp. Technol. Jpn. 8, Pm7.

Matsuzaka, Y., Yamagami, T., Namiki, M. et al. [2000] Adv. Space Res. 26(9), 1365.

Mori, O., Funase, R., Shirasawa, Y. et al. [2014] Trans. Jpn. Soc. Aeronaut. Space Sci. Aerosp. Technol. Jpn. 12, Tk19.

Moritomo, S., Yamanouchi, T., Honda, H. et al. [2009] J. Atmos. Ocean. Technol. 26, 2182.

Nakashino, K. [2012] Trans. Jpn. Soc. Aeronaut. Space Sci., Aerosp. Technol. Jpn. 10, PC19.

Niita, T., Torii, S., Kasahara, K. et al. [2015] Adv. Space Res. $\mathbf{5 5}, 753$.

Nishimura, J. [1993] Adv. Space Res. 13(2), 77.

Nishimura, J. \& Hirosawa, H. [1981] Adv. Space Res. 1, 239.

Saito, Y., Akita, D., Fuke, H. et al. [2012] Adv. Space Res. 49, 613.

Saito, Y., Iijima, I., Izutsu, N. et al. [2006] Adv. Space Res. 37, 2026.

Saito, Y., Yamagami, T., Matsuzaka, Y. et al. [2002] Adv. Space Res. 30(5), 1159.

Shirasawa, Y., Mori, O., Sawada, H. et al. [2009] Demonstration of solar sail deployment system using a high altitude balloon, in Proc. 27th Int. Symp. Space Technology and Science, July 5-12 2009, Tsukuba, Japan, 2009-d-36.

Takahashi, S., Aoki, S., Hamada, K. et al. [2016] Prog. Theor. Exp. Phys. 2016(7), 073F01.

Yamagami, T., Ohta, S., Namiki, M. et al. [1998] Adv. Space Res. 21(7), 983.

Yamagami, T., Saito, Y., Matsuzaka, Y. et al. [2004] Adv. Space Res. 33, 1653.

Yoshida, T., Akita, D., Fuke, H. et al. [2008] Adv. Space Res. 42, 1619 . 